\title{
ABSENCE OF THE PULMONARY VALVE WITH VENTRICULAR SEPTAL DEFECT
}

\author{
BY \\ A. W. VENABLES \\ From the Royal Children's Hospital, Melbourne, Australia \\ Received August 14, 1961
}

Congenital absence of the pulmonary valve is a rare anomaly. It may occur alone causing isolated pulmonary regurgitation. This phenomenon appears to be of uncertain ultimate physiological importance (Lendrum and Schaffer, 1959; Collins et al., 1960) although it has been recorded as a cause of intra-uterine heart failure (Smith et al., 1959). Absence of the pulmonary valve may also complicate ventricular septal defect both with and without infundibular stenosis. Miller et al. (1958) have recorded six cases of absent pulmonary valve, ventricular septal defect, and infundibular stenosis, presenting a rather characteristic syndrome.

Absence of the pulmonary valve with ventricular septal defect but without infundibular stenosis has been described by Campeau et al. (1957), Onesti and Harned (1958), Smith et al. (1959), Vlad et al. (1960), and others. Heart failure ensued in these cases at various ages from infancy to 32 years. The small number of such cases yet recorded offers justification for reporting two further cases of absence of the pulmonary valve complicating ventricular septal defect in infants with intractable heart failure.

\section{CASE RePorts}

Case 1. J. B. was a female baby, the first-born of twins delivered three weeks prematurely on June 3, 1959, at the Box Hill and District Hospital, Melbourne. Delivery was by breech following cord prolapse. Her twin has no known cardiac defect. One of a previous set of twins died soon after birth with congenital heart disease, the nature of which is unknown. Of two elder siblings, one has had a ventricular septal defect complicated by infundibular stenosis repaired under cardiopulmonary bypass.

Clinical Findings. A cardiac murmur was first detected in J.B. on the second day of life. It was diffuse, loud, and primarily systolic. At the pulmonary area there was also a loud diastolic component giving a "to and fro" quality suggesting semilunar valve regurgitation. Pulmonary closure could not be identified. The pulses were normal. The electrocardiogram was normal for age and the initial X-ray was normal.

The baby failed to thrive. At three weeks of age she appeared to be in cardiac failure and was given appropriate treatment. In addition she developed biphasic stridor with rib retraction, suggesting tracheal obstruction. Progressive deterioration occurred with considerable increase in heart size as shown by X-ray. Although a barium swallow showed merely a large left lateral indentation due to the pulmonary artery, thoracotomy was performed at the age of $\mathbf{4 0}$ days. Following this the baby died.

Necropsy Findings. The significant findings in the cardiovascular system were as follows.

Systemic and pulmonary venous drainage was normal. The right atrium was dilated. The coronary sinus was large without evidence of a left superior vena cava. The foramen ovale was patent. Both ventricles were hypertrophied. There was a ventricular septal defect approximately $6 \mathrm{~mm}$. in diameter immediately under the septal cusp of the tricuspid valve, with no muscle rim beneath the valve ring.

The pulmonary valve ring measured $16 \mathrm{~mm}$. in circumference. There were no valve cusps, the valve being represented by small nodules of tissue about 1 to $2 \mathrm{~mm}$. in diameter along the line of the valve ring 
(Fig. 1). The pulmonary trunk and its main branches were grossly dilated. The aortic valve and aorta were normal. There were also patches of bronchopneumonia and bilateral pleural effusions. No other developmental abnormalities were present.

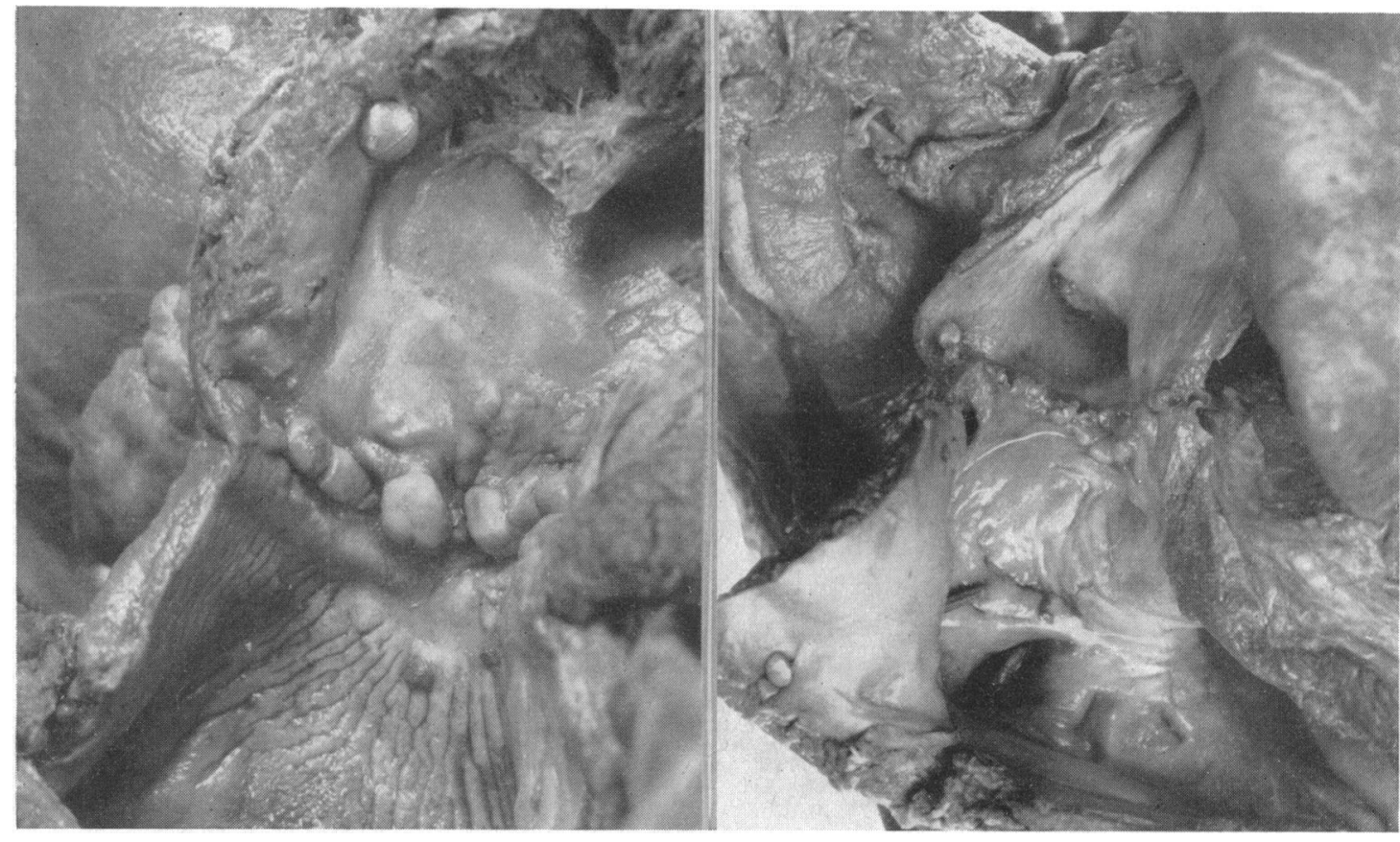

FIG. 1.-Case 1. Pulmonary valve ring cut to show nodules of tissue representing pulmonary valve cusps. Gross dilatation of pulmonary trunk and its main branches. Magnification $\times 3$.
Fig. 2.-Case 2. No pulmonary valve cusps are present; they are replaced by a line of fine beads of tissue at the level of the valve ring. Considerable dilatation of pulmonary trunk. Magnification $\times 1 \cdot 5$.

Case 2. C.S., a female infant, was admitted to the Royal Children's Hospital, Melbourne on September 23, 1959, aged two weeks. Delivery had been normal at term after an uneventful first pregnancy. The baby had been difficult with feedings since birth, tiring readily. Her weight had fallen from $2.75 \mathrm{~kg}$. at birth to $2.56 \mathrm{~kg}$. at two weeks. She was dyspnœic with slight cyanosis on exertion.

Clinical Findings. Examination of the heart showed a loud systolic murmur heard over the whole chest and conducted even to the arms. There was also a diastolic murmur maximal at the pulmonary area where there was a characteristic "to and fro" effect. Pulmonary valve closure could not be defined by auscultation. The pulses were of normal volume. The systolic arterial pressure was approximately $100 \mathrm{~mm} . \mathrm{Hg}$ but the diastolic pressure could not be measured. There were moist sounds posteriorly over both lungs.

An X-ray of the chest showed cardiac enlargement with an unusual contour suggesting a large pulmonary artery and dilated outflow tract of the right ventricle. There were considerable changes in the lung fields.

The cardiogram showed right ventricular preponderance.

Despite routine therapy for cardiac failure the baby died $5 \frac{1}{2}$ days after admission, aged 19 days.

Necropsy Findings. The significant findings were confined to the cardiovascular system, and were as follows. The heart was grossly enlarged, with predominant increase in size of the right ventricle which showed considerable dilatation. Immediately below the septal cusp of the tricuspid valve there was a large ventricular septal defect approximately $8 \mathrm{~mm}$. by $6 \mathrm{~mm}$. in size, with no rim of muscle between the defect and the tricuspid valve ring. The pulmonary valve ring measured $20 \mathrm{~mm}$. in circumference. There were no pulmonary valve cusps, these being represented by a line of fine beads of tissue at the level of the valve ring (Fig. 2). The pulmonary trunk and its branches were considerably dilated. The findings elsewhere were compatible with cardiac failure. There were no other developmental abnormalities. 


\section{Discussion}

Isolated pulmonary regurgitation seems to be of uncertain significance, but it may be of small physiological consequence. Absence of the pulmonary valve in circumstances increasing the volume of regurgitant blood makes the condition of far greater importance. For instance Smith et al. (1959) have cited the high pressure in the fœtal pulmonary artery in its continuity with the descending aorta as a significant factor in their case of intrauterine heart failure.

A large ventricular septal defect with considerable left-to-right shunt and equilibrated right ventricular and systemic pressures may itself lead to heart failure in infancy. Complication of this lesion by absence of the pulmonary valve adds the load of free regurgitation of blood into the right ventricle from the high pressure pulmonary circuit. The volume load of the right ventricle is thus greatly increased. By this means intractable heart failure may be induced in early infancy as in the case of Onesti and Harned (1958) and the two currently described. That the load may be better tolerated and the onset of heart failure delayed is shown by the man reported by Campeau et al. (1957), who died aged 32 years.

The report by Miller et al. (1958) shows that the presence of infundibular stenosis in addition to the ventricular septal defect does not prevent the onset of failure. Their patients had bidirectional shunts and therefore probably did not have severe infundibular stenosis.

A further example of slightly different type in which absence of a true pulmonary valve was associated with stenosis at "valve" level and a ventricular septal defect, without evidence of failure, has been seen at the Royal Children's Hospital, Melbourne.

K.H., a girl aged 11 years, was found to have a large ventricular septal defect with bidirectional shunting, in association with evidence of pulmonary valve stenosis and regurgitation, and aneurysmal dilatation of the pulmonary trunk and its main branches. The right ventricular pressure was $100 / 0 \mathrm{~mm}$. $\mathrm{Hg}$ and the pulmonary artery pressure $18 / 8 \mathrm{~mm}$. $\mathrm{Hg}$. No attempt was made to calculate the regurgitant flow by dye studies, but the diastolic murmur indicating pulmonary regurgitation was faint. The was no evidence of heart failure. At operation the pulmonary valve was represented by a ring of tissue about $3 \mathrm{~mm}$. thick and $10 \mathrm{~mm}$. internal diameter, without any evidence of cusp formation. Using a Kay-Cross oxygenator, Mr. George Westlake successfully repaired the ventricular septal defect with a teflon patch, and relieved the obstruction by incision and dilatation of the ring. In this girl regurgitation was probably mild as a result of the level of pulmonary arterial pressure.

The two cases initially described in this report presented a picture closely resembling those already recorded by other authors. The loud diffuse systolic murmur may well have received contributions both from the ventricular septal defect flow and from turbulence due to the even greater flow across the pulmonary ring. The diastolic murmur resulting in the characteristic "to and fro" quality as described by others indicated pulmonary regurgitation when associated, as in these cases, with normal peripheral arterial pulses. Both patients showed gross dilatation of the pulmonary trunk. In one this led to actual tracheal compression. Aneurysmal dilatation of the pulmonary trunk is a feature of the cases previously recorded.

Both of the patients now presented exhibited intractable cardiac failure in infancy. Their features presented a fairly clear and diagnosable syndrome worthy of attention. Normal pulses excluded aortic regurgitation as the cause of the diastolic murmur, which by its intensity indicated considerable regurgitation. The murmurs were clearly "to and fro," and this circumstance appeared to exclude fistulæ between the aorta and right heart, patent ductus, and aorto-pulmonary window, all of which are causes of continuous murmurs. It should be noted, however, that Smith et al. (1959) described the murmur in their first patient, aged four years, as "continuous." As a result of the experience of the first case, the diagnosis was suspected in life in the second, but it was not confirmed until necropsy.

It would seem important to make this diagnosis in life. Reflection suggests that banding the main pulmonary artery, as has been performed in infancy for ventricular septal defect with large left-to-right shunt, might offer considerable benefit. Such a procedure would reduce left-to-right shunt at ventricular level. It would, in addition, reduce the regurgitant flow by lowering pulmonary artery pressure and by providing a fixed narrowing between the pulmonary trunk and the 
right ventricular cavity as an obstruction to that flow. Such a hæmodynamic situation was probably existing in the third case reported, although in the absence of estimation of regurgitant flow the analogy may not be entirely valid. Banding would, however, seem worthy of trial in infants with this syndrome who are in heart failure and by virtue of their size, are unsuitable for direct repair of their ventricular septal defects.

\section{SUMMARY}

Two patients have been described with absence of the pulmonary valve complicating ventricular septal defect in infancy.

Both patients presented a similar, probably characteristic, picture with intractable heart failure in early infancy, associated with a loud, diffuse systolic murmur, a "to and fro" murmur at the pulmonary area, marked dilatation of the pulmonary trunk, and a normal arterial pulse.

It is suggested that such infants might benefit greatly by banding the main pulmonary artery.

Thanks are due to Dr. T. G. Maddison and Dr. B. W. Neal for requesting consultation on Case 1 at the Box Hill and District Hospital, Melbourne, and to Dr. Maddison for referring Case 2 to the Royal Children's Hospital, Melbourne.

Necropsies were carried out in the Department of Pathology at the Royal Children's Hospital, Melbourne by Dr. Schiavone (Case 1) and Dr. J. Fraillon (Case 2).

\section{REFERENCES}

Campeau, L. A., Ruble, P. C., and Cooksey, W. B. (1957). Circulation, 15, 397.

Collins, N. P., Braunwald, E., and Morrow, A. C. (1960). Amer. J. Med., 28, 159.

Lendrum, B. L., and Schaffer, A. B. (1959). Amer. Heart J., 57, 298.

Miller, R. A., White, H., and Lev, M. (1958). Circulation, 18, 759.

Onesti, S. T., and Harned, H. S., Jr. (1958). Amer. J. Cardiol., 2, 496.

Smith, R. D., DuShane, J. W., and Edwards, J. E. (1959). Circulation, 20, 554.

Vlad, P., Weidman, M., and Lambert, E. C. (1960). Amer. J. Dis. Child, 100, 640. 